\title{
Pengaruh Latihan Keseimbangan Terhadap Peningkatan Konsentrasi Belajar Mahasiswa
}

\author{
Toto Aminoto \\ Jurusan Fisioterapi Poltekkes Kemenkes Jakarta III \\ e-mail: aminoto95@yahoo.com
}

\section{ARTICLE INFO}

Article history:

Received 5 April 2018

Revised 16 July 2018

Accepted 20 July 2018

\section{Keyword:}

Balancing Exercise

Concentration of Learning

Student

DOI:http://dx.doi.org/10.30604/jika.v3i2.88

\begin{abstract}
A B S T R A C T
The ability to the concentration of learning is very important in order to obtain the knowledge given by the lecturer. Thus expected students at the time of exams can do the problem correctly. One form of effort to increase the concentration is with the Balance Exercise. This study aims to prove the influence of Balancing Exercise on student learning concentration. The benefits of this research is to provide therapy for students who have learning difficulties by increasing the concentration of learning to get better learning outcomes. The population in this study is all students in Campus STIE Indonesia Kota Bekasi as many as 520 people. The sampling technique used is purposive sampling. This research uses quasi experimental method with pre and post test design two group design The samples used during the study amounted to 86 people. The samples were divided into two groups namely the treatment group and the control group, each of which amounted to 43 people. Statistical analysis used is paired $t$ test and $t$ independent test. Measurement of learning concentration by using Stroop test mini card. The result showed that the control group produced the sign value of 0.392 so it can be concluded that there was no change of mean before and after intervention. While in the treatment group the value of sign 0.00 which can be interpreted that there is a change in mean values before and after the intervention of balance exercise. The result of the calculation of the difference of the average value of the treatment group was 14.26 while the control group was 0.74 . This result shows that the treatment group is higher than the control group. The conclusion of this research is balance exercise has a significant effect on student concentration.
\end{abstract}

Copyright (C) 2018, Jurnal Aisyah: Jurnal Ilmu Kesehatan.

\section{PENDAHULUAN}

Konsentrasi memegang peranan penting bagi mahasiswa untuk dapat memahami materi kuliah yang diajarkan oleh dosennya. Dengan memahami materi tersebut akan memudahkan mahasiswa ketika mengerjakan soal-soal ujian. Jika mahasiswa mampu mengerjakan soal dengan baik maka kemungkinan untuk mendapatkan nilai ujian yang lebih tinggi akan mudah terwujud. 
Dengan demikian akan berakibat naiknya nilai Indeks Prestasi Kumulatif (IPK).

Terkait dengan hal tersebut, maka konsentrasi merupakan aspek yang penting bagi mahasiswa dalam mencapai keberhasilan belajar Nuryana (2011). Saat ini proses pembelajaran diperguruan tinggi masih menggunakan sistem satu arah. Dalam sistem tersebut dosen mengharuskan mahasiswa untuk duduk dan memperhatikannya selama lebih dari satu jam. Hal ini menyebabkan mahasiswa mengalami kelelahan dan ketegangan. Disamping itu kejenuhan dapat muncul akibat tempat duduk dalam deretan bangkubangku yang menghadap ke depan (DePorter, 2000).

Kondisi tempat duduk seperti itu mengakibatkan otot-otot syaraf mengalami ketegangan sehingga keadaan otak akan mengalami kekurangan energi dengan demikian asupan oksigen dan aliran darah menuju ke otak pun tidak tidak optimal. Apabila otak kekurangan energi, maka hal ini dapat menyebabkan otak tidak berfungsi secara optimal dan dapat menyebabkan penurunan konsentrasi belajar pada mahasiswa. Saat ini mahasiswa di kampus STIE Indonesia Kota Bekasi masih ditemukan mahasiswa semester 1-4 yang nilai IPK nya masih rendah. Menurut Humas STIE Indonesia kota Bekasi saat ini proporsi IPK yang kurang dari 3,00 mencapai hampir 30 persen dari jumlah mahasiswa yang ada. Penyebab nilai IPK rendah salah satunya karena mahasiswa tersebut sulit untuk belajar. Kesulitan tersebut salah satunya tidak bisanya berkonsentrasi pada saat terjadi proses belajar mengajar di kelas. Untuk itu, dibutuhkan suatu treatment yang dapat membantu mahasiswa untuk memiliki kemampuan konsentrasi belajar yang baik. Konsentrasi belajar dapat dilatih dengan menggunakan Latihan Keseimbangan.

Pengertian keseimbangan adalah kemampuan dalam hal mempertahankan kesetimbanan tubuh ketika berada di berbagai posisi (O'Sullivan, 2011). Definisi menurut Irfan
(2012) keseimbangan adalah daya kemampuan dalam mempertahankan kondisi pusat gravitasi terutama pada bidang tumpu ketika saat posisi tegak. Hendra (2009) berpendapat konsentrasi adalah sumber kekuatan pikiran dan bekerja berdasarkan daya ingat dan lupa dimana pikiran tidak dapat bekerja untuk lupa dan ingat dalam waktu bersamaan. Apabila tingkat konsentrasi seseorang mulai mengalami pelemahan maka orang tersebut cenderung mudah melupakan suatu hal dan sebaliknya apabila konsentrasi merasa cukup kuat maka orang tersebut akan mudah mengingat dalam waktu yang lama.

Salah satu alat untuk mengukur konsentrasi belajar adalah menggunakan Stroop test mini card. Metode ini pertama kali dikenalkan oleh John Ridey pada tahun 1935. Tesini digunakan para psikolog untuk menilai fungsi kognitif seseorang terutamadalam fungsi ekskutif, perhatian yang selektif terhadap informasi spesifik dan menghambat segala kejadian yang mengganggu dalam pengambilan keputusan.

Dalam melaksanan tes ini,responden harus dalam keadaan yang nyaman, misalnya dengan suhu yang terkontrol, bebasbising lingkungan untuk meminimalisir berbagai hal yang dapat mengganggu.Tujuan tes ini untuk menilai kecepatan dan akurasi responden dalam menjawab.

\section{METODE}

Penelitian ini menggunakan metode quasi eksperimental dengan rancangan pre-post with two group design (Sugiyono, 2010). Penelitian ini bertujuan melihat efek atau pengaruh Latihan Keseimbangan terhadap Konsentrasi Belajar pada mahasiswa STIE Indonesia Kota Bekasi. Populasi dalam penelitian ini adalah seluruh mahasiswa di Kampus STIE Indonesia Kota Bekasi sebanyak 520 orang. Sampel yang digunakan saat penelitian berjumlah 86 orang. Dari jumlah tersebut dibagi menjadi dua kelompok yaitu kelompok perlakuan dan kelompok 
kontrol yang masing-masing berjumlah 43 orang.

Teknik pengambilan sampel yang digunakan adalah purposive sampling yaitu teknik pengambilan sampel berdasarkan pertimbangan tertentu (Supranto, 2011). Pengumpulan data pada penelitian ini adalah data primer atau data langsung dari responden. Untuk tingkat konsentrasi dihitung dengan menggunakan Stroop Test Mini Card. Tes ini menggunakan sebuah kartu yang berisi 100 kata dengan ejaan dan warna yang berbeda. Responden diinstruksikan untuk menyebutkannya selama
45 detik. Nilai pengukurannya adalah bila responden dapat menjawab $<20$ sangat rendah, 20 - 39 rendah, 40 - 59 sedang, 60 80 tinggi dan $>80$ sangat tinggi. Baik kelompok kontrol maupun kelompok perlakuan diambil data konsentarsinya. Selanjutnya kelompok perlakuan diberi latihan keseimbangan sedangkan kelompok kontrol tidak diintervensi. Pada kurun waktu tertentu kemudian masing-masing kelompok diambil data konsentrasinya. Penelitian ini dilaksanakan di kampus STIE Indonesia Kota Bekasi pada bulan November 2017 sampai bulan Januari 2018.

\section{HASIL DAN PEMBAHASAN}

Tabel 1. Diskripsi Responden

\begin{tabular}{lcccc}
\hline \multirow{2}{*}{ Jenis Kelamin } & \multicolumn{2}{c}{ Kelompok Perlakuan } & \multicolumn{2}{c}{ Kelompok Kontrol } \\
\cline { 2 - 5 } & f & \% & f & \% \\
\hline Laki-laki & 17 & 40 & 21 & 49 \\
Perempuan & 26 & 60 & 22 & 51 \\
\hline Tingkat Semester & & & & \\
\hline Semester I & 4 & 9 & 7 & 16 \\
Semester II & 16 & 37 & 11 & 26 \\
Semester III & 11 & 26 & 11 & 26 \\
Semester IV & 12 & 28 & 14 & 32 \\
\hline
\end{tabular}

Berdasarkan tabel 1 dapat diketahui untuk kelompok Perlakuan jumlah responden yang jenis kelamin laki-laki berjumlah 17 orang atau 40 persen dan jenis kelamin perempuan berjumlah 26 orang atau 60 persen, Dengan demikian responden didominasi oleh jenis kelamin perempuan Sedangkan kelompok kontrol diketahui jumlah responden yang jenis kelamin laki-laki berjumlah 21 orang atau 49 persen dan jenis kelamin perempuan berjumlah 22 orang atau 51 persen, Dengan demikian responden didominasi oleh jenis kelamin perempuan

Berdasarkan tabel 1 pada kelompok perlakuan dapat diketahui jumlah responden yang duduk di semester I sebanyak 4 orang atau 9 persen, Semester II sebanyak 16 orang atau 37 persen, semester III sebanyak 11 orang atau 26 persen dan semester IV sebanyak 12 orang atau 28 persen. Sedangkan kelompok kontrol dapat diketahui jumlah responden yang duduk di semester I sebanyak 7 orang atau 16 persen, Semester II sebanyak 11 orang atau 26 persen, semester III sebanyak 11 orang atau 26 persen dan semester IV sebanyak 14 orang atau 32 persen.

Untuk itu langkah pertama adalah uji normalitas antara post dan pre pada masingmasing kelompok. Uji normalitas menggunakan uji Kolmogorov Smirnov Hasil uji normalitas masing-masing kelompok dapat dilihat pada tabel 2. berikut: 
Tabel 2. Uji Normalitas

\begin{tabular}{lcccc}
\hline Kelompok & $\begin{array}{c}\text { Mean Sebelum } \\
\text { Intervensi }\end{array}$ & Keterangan & $\begin{array}{c}\text { Mean Sesudah } \\
\text { Intervensi }\end{array}$ & Keterangan \\
\hline Kontrol & 0,266 & Normal & 0,613 & Normal \\
\hline Perlakuan & 0,122 & Normal & 0,130 & Normal \\
\hline
\end{tabular}

Hasil uji normalitas pada tabel 2 terlihat bahwa data kelompok kontrol sebelum dan sesudah terditribusi normal begitu juga untuk kelompok perlakuan menunjukan ditribusi normal. Dengan demikian dilanjutkan dengan uji paired t tes.

Tabel 3. Uji Paired t tes

\begin{tabular}{lcccccc}
\hline Kelompok & $\begin{array}{c}\text { Mean } \\
\text { Sebelum } \\
\text { Intervensi }\end{array}$ & $\begin{array}{c}\text { Standar } \\
\text { Deviasi } \\
\text { Sebelum } \\
\text { Intervensi }\end{array}$ & $\begin{array}{c}\text { Mean } \\
\text { Sesudah } \\
\text { Intervensi }\end{array}$ & $\begin{array}{c}\text { Standar } \\
\text { Deviasi } \\
\text { Sesudah } \\
\text { Intervensi }\end{array}$ & Sign & Keterangan \\
\hline Kontrol & 40,98 & 8,71 & 41,72 & 11,65 & 0,392 & Signifikan \\
\hline Perlakuan & 43,70 & 15,60 & 57,95 & 13,85 & 0,00 & Tidak Signifikan \\
\hline
\end{tabular}

Hasil analisis pada tabel 3 menunjukan bahwa untuk kelompok kontrol sebelum dilakukan intervensi nilai mean sebesar 40,95 $\pm \quad 8,71$ hasil ini menunjukan nilai konsentrasinya adalah kategori sedang. Sedangkan sesudah intervensi nilai mean sebesar 41,72 $\pm 11,65$ hasil ini menunjukan nilai konsentrasinya adalah kategori sedang. Hasil uji paired t tes menunjukan nilai sign 0,392 dengan demikian dapat disimpulkan bahwa untuk kelompok ini tidak ada perubahan nilai kategori konsentrasi sebelum dan sesudah. Hal ini karena pada kelompok ini memang tidak diberikan intervensi khusus. Hasil Pengukuran menunjukan bahwa untuk kelompok perlakuan sebelum dilakukan intervensi nilai mean sebesar 43,70 $\pm 15,60$ hasil ini menunjukan nilai konsentrasinya adalah kategori sedang. Sedangkan sesudah intervensi nilai mean sebesar 57,95 \pm 13,85 hasil ini menunjukan nilai konsentrasinya adalah kategori sedang. Hasil uji paired $t$ tes menunjukan nilai sign 0,000 dengan demikian dapat disimpulkan bahwa untuk kelompok perlakuan ada perbedaan mean antara sebelum dan sesudah intervensi. Pada kelompok ini memang diberikan intervensi khusus berupa latihan keseimbangan. Dengan demikian dapat disimpulkan bahwa intervensi latihan keseimbangan mampu meningkatkan konsentrasi belajar.

Tabel 4. Uji Sebelum intervensi antara kelompok kontrol dan perlakuan

\begin{tabular}{|c|c|c|c|c|c|c|}
\hline \multirow{2}{*}{ Kelompok } & \multicolumn{2}{|c|}{ Uji Homogenitas } & \multicolumn{4}{c|}{ Uji t Independent } \\
\cline { 2 - 7 } & Sig & Keterangan & Selisih Mean & Standar Error & Sig & Keterangan \\
\hline $\begin{array}{c}\text { Sebelum Perlakuan - } \\
\text { Sebelum kontrol }\end{array}$ & 0,064 & Homogen & 2,72 & 2,72 & 0,321 & $\begin{array}{c}\text { Tidak } \\
\text { Signifikan }\end{array}$ \\
\hline
\end{tabular}

Untuk membandingkan dua kelompok kontrol dan perlakuan maka sebelumnya harus dibandingkan keadaan sebelum masing-masing kelompok. Dari tabel 4 diatas menunjukan bahwa posisi sebelum untuk kedua kelompok tersebut dihasilkan nilai sign 0,064 yang menunjukan data adalah homogen.
Sedangkan uji kedua kelompok menghasilkan nilai sign 0,321 yang menunjukan bahwa kelompok kontrol sebelum intervensi dan kelompok perlakuan sebelum intervensi tidak ada perbedaan nilai konsentrasinya atau posisinya adalah sama. 
Tabel 5. Uji Normalitas dan Homogenitas

\begin{tabular}{ccccc}
\hline & Uji Normalitas & & \multicolumn{2}{c}{ Uji Homogenitas } \\
\hline Kelompok & Sign & Kelompok & Sign & Kelompok \\
\hline Selisih Kontrol & 0,054 & Selisih Kontrol & 0,054 & Selisih Kontrol \\
\hline Uji Normalitas & Uji Homogenitas & Uji Normalitas & Uji Homogenitas & Uji Normalitas \\
\hline
\end{tabular}

Hasil uji normalitas pada tabel 5 diatas terlihat bahwa data selisih kelompok kontrol dan perlakuan terdistribusi normal. Untuk itu dilakukan Uji 2 rata-rata (independen $t$ test). Pada uji ini terlihat bahwa data adalah tidak homogen.

Tabel 6. Hasil uji perbedaan antara kelompok kontrol dan kelompok perlakuan

\begin{tabular}{lcccccc}
\hline Kelompok & Mean & $\begin{array}{c}\text { Standar } \\
\text { Deviasi }\end{array}$ & $\begin{array}{c}\text { Perbedaan } \\
\text { Mean }\end{array}$ & $\begin{array}{c}\text { Standar } \\
\text { Error }\end{array}$ & Sign & Keterangan \\
\hline Kontrol & 0,744 & 5,64 & 13,51 & 2,16 & 0,001 & Signifikan \\
\hline Perlakuan & 14,26 & 12,99 & & & & \\
\hline
\end{tabular}

Berdasarkan uji hipotesis menggunakan Independent Sample T-test pada tabel 6 diatas didapatkan nilai sign $=0,000$, artinya, ada perbedaan antara kelompok kontrol dan kelompok perlakuan. Nilai mean pada kelompok kontrol sebesar 0,74 sedangkan kelompok perlakuan sebesar 14,26. Hasil penelitian menunjukan mean kelompok perlakuan lebih besar dari kelompok kontrol sehingga dapat disimpulkan bahwa kelompok perlakuan lebih efektif dari kelompok kontrol.

Hasil penelitian menunjukan bahwa pemberian intervensi latihan keseimbangan mampu meningkatkan konsentrasi belajar mahasiswa. Hasil penelitian ini sejalan dengan penelitian yang telah dilakukan oleh Wiwik (2014) dalam penelitiannya tersebut ia meneliti siswa PAUD Taman Belia Candi Semarang. Hasil penelitiannya menunjukan bahwa latihan keseimbangan dapat meningkatkan tingkat tingkat konsentrasi. Hal ini dapat dilihat ketika siswa mampu berjalan di atas versa disc dengan baik tanpa sedikitpun terpeleset.

Disamping itu penelitian ini juga sejalan dengan penelitian yang dilakukan oleh Sumaryanti (2010) dimana telah dilakukan penelitian pada siswa tunagrahita dengan memberikan aktivitas fisik berupa latihan keseimbangan. Hasil menunjukan bahwa konsentrasi anak menjadi meningkat hal ini terlihat dari mudahnya mereka memahami perintah. Dalam penelitian tersebut sampel berjumlah 15 responden yang dipilih melalui teknik Simple Random Sampling.

Setiap gerakan Latihan Keseimbangan mempunyai mekanisme kerja masing-masing dan memiliki beberapa dimensi yang berbeda. Menurut Dennison (2000) yang telah melakukan pembagian otak ke dalam 3 dimensi, yakni dimensi lateralis (otak kirikanan), dimensi pemfokusan (otak depanbelakang), dimensi pemusatan (otak atas bawah). Pada pembagian tersebut maka beberapa dimensi mendapat pembagian tugas tertentu sehingga gerakan latihan yang diperintahkan dapat dilakukan bervariasi.

Latihan Keseimbangan dapat membantu mahasiswa dalam mengkordinasikan beberapa gerakan seperti gerakan mata, gerakan tangan dan gerakan tubuh karena gerakan latihan keseimbangan merupakan bagian dari usaha alternatif alami yang sehat untuk menghadapi ketegangan dan tantangan diri sendiri dan tentunya bagi orang lain (Rahayu, 2017).

Latihan keseimbangan merupakan latihan tersendiri terutama ditujukan dalam rangka membantu untuk meningkatkan kekuatan otot khusus anggota bawah (kaki) dan dalam rangka meningkatkan mekanisme system vestibular/kesimbangan tubuh. Adapun organ yang berperan penting dalam sistem 
keseimbangan tubuh adalah balance perception. Otak, tulang beserta otot mampu bekerja secara bersama-sama untuk menjaga keseimbangan tubuh agar mampu mempertahankan keadaan seimbang dalam rangka mencegah terjadinya jatuh. Jika balance perception berjalan dengan bagus maka konsentrasi akan muncul dengan sendirinya.

\section{KESIMPULAN DAN SARAN}

Kesimpulan: Intervensi Latihan Keseimbangan mampu meningkatkan konsentrasi belajar mahasiswa STEI Indonesia kota Bekasi

Saran: Sebaiknya Latihan keseimbangan ini dijadikan program rutin bagi kampus yang ditujukan bagi mahasiswa dalam rangka meningkatkan mutu akademik kampus STEI Indonesia.

\section{DAFTAR PUSTAKA}

Dennison. P.E., Dennison. GE and Teplihtz J. V. (2004). Brain Gym untuk Bisnis. Batam: Interaksara Batam Center

Surya Hendra. (2009). Menjadi Manusia Pembelajar. Jakarta: Elex Media Komputindo

Irfan, (2009). Keseimbangan Pada Stroke. Diakses tanggal 04/03/2018, dari http://infostroke.wordpress.com/kesei mbangan-pada-stroke/

De Porter. (2000). Quantum Teaching/Learning. Bandung: Kaifa Britton.

Nuryana. (2011). Efektivitas Brain Gym meningkatkan konsentrasi belajar. Jurnal Ilmiah psikologi. Universitas Muhamadiyah Solo.

O’Sullivan, Susan B, dkk. (1981). Physical Rehabilitation Evaluation \& Treatment Procedures. Philadelpia: F.A Davis Company.

Rahayu. (2017). Fenomena Balance Exercise Untuk Meningkatkan Keseimbangan Postural Lanjut. Prosiding Seminar Ilmiah Nasional Kesehatan. ISSN: 2338-2694

Sumaryanti. (2010). Pengembangan Model Pembelajaran Jasmani Adaptif Untuk Optimalisasi Otak Anak Tunagrahita. Jurnal Kependidikan. Vol 40 No 1, Mei 2010. Hal 2944

Sugiyono. (2010). Statistika untuk Penelitian. Bandung: Alfabeta.

Supardi. (2013). Aplikasi statistika dalam Penelitian; Konsep statistika yang Lebih komprehensif. Jakarta: Prima Ufuk Semesta

Supranto. (2011). Statistik: Teori dan Aplikasi. Jilid 2, edisi keenam. Jakarta: Erlangga

Wiwik Dkk. (2014). Peningkatan Keseimbangan Tubuh Melalui 
Berjalan Diatas Versa Disc Pada Anak Kelompok B Paud Taman Belia Candi Semarang. Jurnal Penelitian dalam Bidang Pendidikan Anak Usia
Dini. ISSN 2089-1431. Vol3 No.12. Oktober 2014. 
J urnal Aisyah: J urnal Ilmu Kesehatan, 3(2), Desember 2018, - 124

Toto Aminoto 